\title{
Effective Teaching through Programming Assignments
}

\author{
Sunitha. $\mathbf{P}^{1}$, Uma Boregowda ${ }^{2}$, A.Geethakiran ${ }^{3}$, Margaret. R.E ${ }^{4}$, Vinod.A.M ${ }^{5}$ \\ 1,2,3 Department of Computer Science and Engineering \\ Malnad College of Engineering,Hassan, Karnataka, India \\ 4,5 Department of Master of Computer Applications \\ Malnad College of Engineering,Hassan, Karnataka, India \\ ${ }^{1}$ suniachar@gmail.com \\ 2umaboregowda@gmail.com \\ ${ }^{3}$ geethaagk@gmail.com, \\ 4rem@mcehassan.ac.in \\ 5 vinutaurus@gmail.com
}

\begin{abstract}
Students and educators are the main components of any teaching system wherein educators play an important role. The vision of every educator is to make every student a successful IT professional in the current industry scenario. To meet the requirements of the IT industry, we need to enhance the quality of our students through effective teaching. Many studies have shown that life skills along with technical skill decide the success of a person. Hence, an attempt is made to improve both technical and life skills of students through regular engineering courses, instead of having separate courses on communication skills and ethical values. The idea of enhancing the skills of students through our proposed approach is experimented for the "Algorithm Design and Analysis" course. Our experimented process of effective teaching through programming assignments has given a very satisfactory result and the students are also happy about their accomplishments in the course .
\end{abstract}

Keywords- algorithm analysis and design course, programming, assignment.

\footnotetext{
Sunitha. $\mathbf{P}^{1}$

${ }^{1}$ Department of Computer Science and Engineering Malnad College of Engineering,Hassan, Karnataka, India
}

\section{INTRODUCTION}

'Algorithm' is a step by step process or a procedure or a formula of solving any problem. Hence, the course "Algorithm Design and Analysis (ADA)", can be applied to any engineering field, be it Electronics or Electrical or Mechanical or Civil. Consequently, this course is chosen for experimental analysis for the proposed idea.

Currently, this course is included as a core subject for $2^{\text {nd }}$ year Computer Science Engineering students. It is taught with 4 hours of teaching per week. The course includes several algorithm design techniques which needs to be taught effectively and efficiently. In addition, students are to be given the knowledge of applying the same in real life problems in IT industry. Hence, we need to enhance the quality of problem solving capability among students.

To achieve this, we plan to include written tests, individual assignment and team assignment. The questions for written test were so chosen such that it needs the application of concepts learnt in the course instead of just reproducing the learnt concepts. Further, it gives very less scope for copying because of the nature and complexity of the questions. But during evaluation, the emphasis is on the approach taken to solve the problem rather than only the final answer.

To enforce team work which is one of the main required component in an IT industry, students are made into batches, in a way emulating real life scenario. Each batch is given different problems to be solved. The evaluation includes rigorous presentation and discussion of the solution proposed, their implementation, results obtained and conclusion drawn. Finally, students are encouraged to submit the complete report of their assignment in the IEEE format. The complete process made students to learn to understand problems, make analysis, improve inter-person relation among batchmates, 
more tolerance towards each other and also improve their communication skill.

It is rightly said that journey is as important as the destination. So, the entire process of solving assignment and writing brief reports has helped the students to blossom in multi-dimension. The survey conducted has proven this. We are now looking out to standardize the whole process using rubrics so that it can be applied to a class with large number of students and used by any faculty members for their courses.

According the ACM and IEEE, "Learning objectives are central components of any body of knowledge; basically they capture important elements that are typically absent from a mere list of knowledge topics. They are intended to capture what students are able to do with knowledge." Our proposed approach even helps students and teachers to meet the course objectives which in turn maps to the program outcome. Consequently, it also satisfies the needs of outcome based education.

\section{IMPORTANCE OF THE COURSE}

ADA course is the most important and useful course for any IT professional. It has to be a core subject in the curriculum for a computer science engineering branch. It discusses numerous techniques of solving problems. Some of them are:

1. Divide and Conquer

2. Greedy techniques

3. Branch and bound

4. Dynamic Programming

5. Backtracking

6. NP hard

Hence, this course is more practical oriented rather than theory oriented. Students need more exposure to the practical way of solving a problem. Different application problems need different ways of solving it. Student should have a prior knowledge of data structures, mathematical modelling and a programming language. This course directly and also indirectly affects the better learning of other courses as shown in the Figure 1. Hence, this indicates the need and importance of the course for engineering graduates.

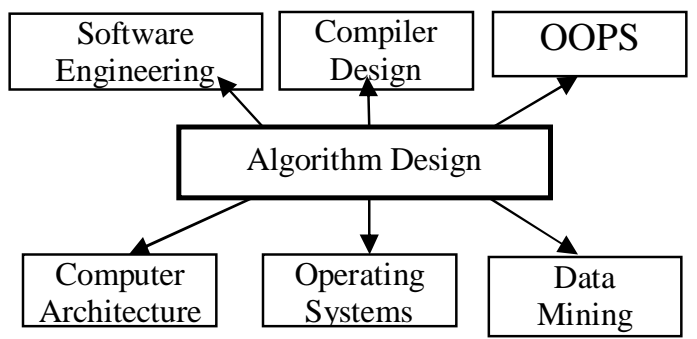

Figure 1 : Courses influenced by ADA

\section{RELATED WORK}

Teaching is an art and a very respectable practice. It enriches the students' lives and gives satisfaction to the teacher. But making students become creative thinkers and problem solvers is an achievement both for the students and for the teacher. Teaching has to be systematic, informative and comprehensive. Teaching has taken different flavours during the past decades.

Traditional method of teaching with black board and chalk is teacher-centered. It has many drawbacks which can be summarized as:

- Lack of complete theoretical knowledge: In the theory session, teachers just explain the different strategies of solving problem. Simple examples are taken to explain the concept of the algorithm. For instance, sorting a set of numbers using bubble sort. Teachers illustrate the concept by taking some 10 numbers. But he/she cannot illustrate the same using 100-1000 numbers to understand the time complexity of the algorithm and compare the same with other algorithms.

- Incomplete practical knowledge: During regular lab sessions, students solve the given assignments using the simple data structures taught in the class. But, they will not be able to judge as to which data structure to use for what sort of problems when need to solve for huge data in real time applications.

- Limitations in application of the knowledge: Students will not be able to analyse as to which techniques are to be used to solve a given real time problem and the most efficient one.

In the view of enhancing the problem solving techniques among students, people have done large amount of research for the past 30 decades. They have tried several different ways for different courses to improve the analysis and design techniques in solving any problem.

Considering the ADA course, [1] Authors have analysed that one can enrich teaching methods by introducing multimedia teaching like presentations, animations of concepts, and use of content rich information. All these methods will not only save teaching time but also reduces the time in making concepts more strong among students. University curriculum has to be designed with more practical and real time application oriented concepts. It should range from easy to complex, covering different levels of students. Students should be allowed to participate while demonstrating new concepts.

Pedagogical methods are also being applied while teaching ADA course [2] in different phases. In the first phase, students are given individual assignments. They are supposed to dissect and understand the problem statement, analyse as to what is the input to be given, what is the output to be obtained, data structures needed and complexity of the problem. In the next phase, students are instructed to design the algorithm, applying the relevant methods that are being taught. Finally, students implement the given problem using $\mathrm{C} / \mathrm{C}++$ or any language. This way of making students to learn the concepts will help them to understand it better and enable to apply the concepts for any application problems. It even helps them to build design ability and in turn improves their problem solving capability.

Innovative techniques like filling teaching and 
heuristic teaching are experimented by Luo et.al [3] to improve effective teaching. In filling teaching, concepts are explained theoretically by using numerous examples and in heuristic teaching students are allowed to solve, analyze, criticized by firing questions by the teachers. This helps them to infer other facts, gain experience and think more flexibly . Finally, it inspires students to think individually about basic principles of different concepts in algorithms and apply them in solving real time problems.

Student's problem in understanding the course should be identified by the teacher [6] and accordingly new teaching methods should be applied by preparing new course material, create interest among students by conducting competitions and group discussions in the classrooms.

Online Judgment System(OJS) is also tried [7] to improve the programming skills of the students in the ADA course. In OJS, many problems are prepared on each concept of algorithms being taught. Students have to solve the assignment anywhere and post their code online (OJS) which will be evaluated by the teacher. OJS provides an environment to enter the code and execute it online. This approach has also encouraged students to work independently.

Learning with teaching can be combined with research approach [5]. As ADA course is considered necessary to many other disciplines of engineering, Research-Oriented teaching becomes an elementary factor. It is justified that the course is creative in nature and it needs to master in mathematical knowledge to understand classical algorithms. Teachers guide students in every step of his/her learning the course. This improves the research - thinking, innovative and solving ability.

In the proposed method, we have incorporated few innovative methods to improve effective teaching which have been tried individually in the previous works. Entire course is taught with individual assignment, written tests, quizzes and team assignments. This has helped students to improve their learning capability, solving I. ability and even thinking in different ways of solving the problem

\section{PROGRAM (STRUCTURE)}

Algorithms are being taught in different phases. It can be summarized as given in Figure 2.

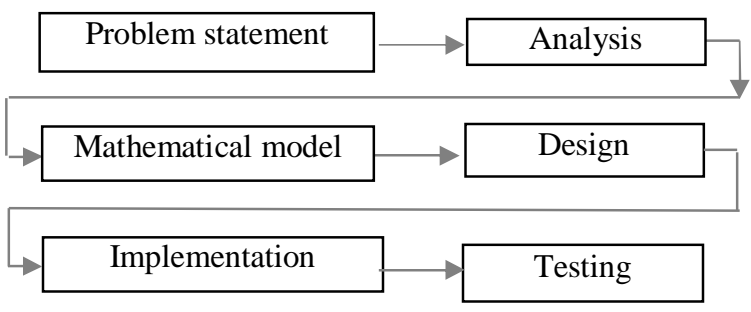

Figure 2: Different phases of teaching algorithms

In problem statement phase, students are taught to dissect the statement and identify the input / data needed and the output to be obtained. Analysis involves the algorithm to be used and its complexity obtained while solving the problem. Complexity is analysed by drawing a mathematical model. The data structure needed is decided in the next phase. Finally, any programming language is used to implement the designed model.

To strengthen the theoretical concept, students are given individual assignment at the end of each concept covered. They are given flexibility to use any programming language for implementation. Their assignment is tested by checking output for all possible input. Presentation involving all the phases of implementation, as mentioned above, is given by every student.

During the presentation of each student, teachers guide them to analyse, criticize and solve by asking questions to them. This way of evaluating students will make them strong in basic concepts of algorithms. It also improves their skills in problem solving, communication and programming .

Quizzes are conducted by giving a set of 10-20 questions after the completion of every concept. Quiz answer scripts are randomly redistributed among the students and answers are also provided for evaluation. They are made to evaluate the quiz answer papers of their class mates. This process helps them to be impartial and know the process of evaluation. Written tests are also conducted and the faculty evaluates them

Team work has become an integral part of this course. It motives and demonstrates a need of good communication skills, co-operation, time management, interdependence, co-ordination and negotiation. They can share their experience among others and even get exposed to technical skills. Team involvement helps students to initiate discussions of the subject matter. Students also develop insights by exchanging ideas and clarifying doubts with class mates and lecturers. It helps them to carefully prepare to achieve satisfactory results.

To achieve the above attributes for a student, they are given group assignments. A batch of 3-4 students is given an algorithm assignment of higher complexity compared to individual assignment. The scheme of evaluation process used for individual assignment is also applied for group assignment. At the end of the course, students are made to present their team assignment work in the form of a technical paper and encouraged to publish the same in a conference. This helps them to add feather to their achievements in academics.

Not every student is perfect, neither any student is failure. Hence, evaluation should be fair enough for all category of students. Final marks for this course is distributed as shown in the Table 1.

Table 1: Marks Distribution

\begin{tabular}{|l|l|l|}
\hline Sl.No & Component & Marks \\
\hline 1. & Internal Test & 20 \\
\hline 2. & Quiz & 5 \\
\hline 3. & Individual Assignment & 10 \\
\hline 4. & Team assignment & 15 \\
\hline
\end{tabular}




\begin{tabular}{|l|l|l|}
\hline 5. & Semester End Exam & 50 \\
\hline
\end{tabular}

While evaluating individual and group assignment following points are considered

1. Understanding of the problem statement

2. Algorithm used to solve

3. Results and its application

4. Confidence level while presenting

5. Slide preparation

6. Each members contribution in solving the problem

To encourage the students who are below average and appreciate the cream students for their problem solving ability, all the scores below the minimal marks are freezed at minimum score and the rest are accordingly moderated.

\section{RESULTS AND ANALYSIS}

Our strategy of making students learn through coding assignments has a positive affect compared to traditional method of teaching the ADA course. It has been observed that semester end examination pass percentage has improved by $7 \%$ to $10 \%$ as shown in Figure 3 .

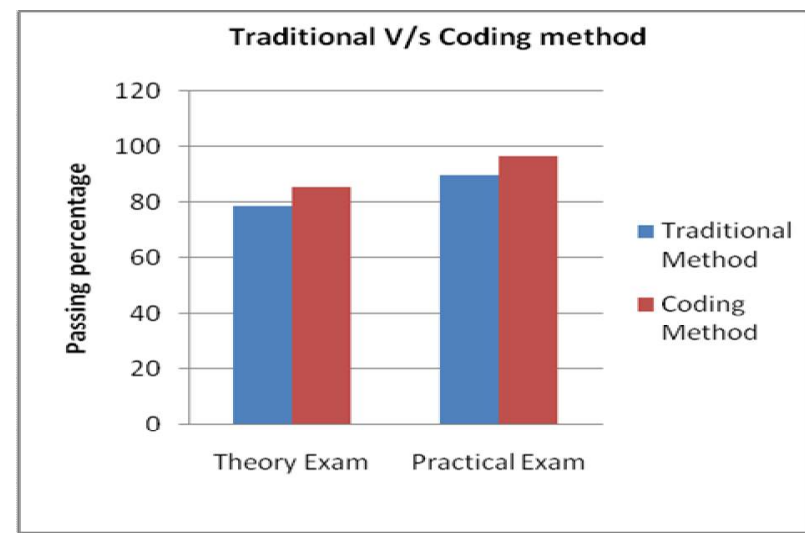

Figure 3: Comparison of Traditional versus Proposed method

By giving presentations, their confidence level has boosted up, their communication skills has even improved to a greater extent. At the outset, each student is capable of writing a paper for a conference, which adds credit to his/her carrier and even adds weight-age for his/her campus recruitment.

Our strategy of effective teaching achieves the following program outcomes which would have been very difficult to achieve otherwise:

- $\quad$ an ability to identify, analyse a problem, and define the computing requirements appropriate to its solution.

- an ability to work effectively in teams to accomplish a common goal.

- an ability to communicate effectively with a range of audiences.

- $\quad$ an ability to use current techniques, skills, and tools necessary for computing practice.
Students have given a positive response for this method of understanding and learning the algorithms course. They have suggested to apply the same technique to teach other subjects also like data structure, system software, software engineering, operating systems, compiler design, programming languages, etc.

\section{CONCLUSION}

Our goal to motivate students to improve their problem solving and programming ability has been achieved to a greater extent. It is also proven that problem solving and thinking ability of students has enhanced significantly through coding assignments. Our novel approach also provides a platform for students to hone their skill sets. Students get an opportunity to interact with more knowledgeable peer students and in turn gain valuable experience in solving real application problems. Personal relation among students and teachers has strengthened and thus fostering a feel of community within a department.

\section{REFERENCES}

[1] Yan Shaohong,, Liu Baoxiang,, Feng Lichao,J iNan (2010), " Some Thoughts on "Algorithm Design and Analysis", Teaching Reform " in 2nd International Conference on Industrial Mechatronics and Automation [2] Jayalakshmi G Naragund and Vidya S Handur, (2013), "Educationally Effective Teaching of Design and Analysis of Algorithms", IEEE, Innovation and Technology in Education (MITE).

[3] Xiong Luo, Zhaoshun Wang, Junwei Zhou, and Yi Chen, (2013), "An Integrated Application of Educational Technologies for "Algorithm Design and Analysis" Course , ICETMS 2013

[4] Byron S. Gottfried, "Teaching Computer Programming Effectively Using Active Learning “

[5] Xuemin Zhang, Zenggang Xiong, Yaomin Ding, Guangwei Wang \& Conghuan Ye, (2014), "Researchoriented teaching of an Algorithm Design and Analysis course " in World Transactions on Engineering and Technology Education, (12)3.

[6] Qing Li Weiwei Chen, Yanqin Tang, (2013), "Teaching Reform and Practice of "Algorithms and Data Structures" , ICETMS.

[7] Duanyang Zhao, Qingxiang Xu, (2012),"Research and Practice on Algorithm Analysis and Design Course Teaching Based on Online Judge”, ICCIA . 
Journal of Engineering Education Transformations, Volume, No, Month 2015, ISSN 2349-2473, eISSN 2394-1707 